\title{
TEOLOGÍA Y NARRACIÓN EN LAS HOMILÍAS SOBRE LA DORMICIÓN DE GERMÁN DE CONSTANTINOPLA
}

ELISA FERRER $^{1}$

RESUMEN: Hacia los siglos VII-VIII, la fiesta de la Dormición de la Virgen, que celebraba el misterio de su muerte y resurrección, estaba consolidada. Entre los escritos relativos a la Dormición de María se cuentan tres homilías escritas por Germán, Patriarca de Constantinopla. La edición de Migne las presenta como escritos diferentes, pero se cree que el autor escribió dos textos y que luego, para adecuarse al esquema de "trilogías", la primera fue dividida. Puesto que se advierte gran diferencia entre las primeras (con pasajes de especulación teológica y otros doxológicos) y el estilo narrativo de la tercera, parece oportuno profundizar en la relación entre el objetivo con el que Germán escribió estas homilías y la estructura que les dio. Este trabajo pretende establecer que en las dos primeras homilías -de estilo más elevado-, el autor profundiza en puntos doctrinales que iluminan la narración de la última. No se trata de dos bloques unificados sólo para la ocasión, sino que se reconoce la intención de proporcionar en las primeras la clave para entender los hechos que relata la tercera.

Palabras clave: Bizancio - narración - teología - homilética.

ABSTRACT: Around the 7th-8th centuries, the feast of the Dormition of the Virgin, celebrating both the mystery of her death and that of her resurrection, was already fully consolidated. Among the writings related to the Dormition of Mary, there are three homilies written by Germanos, Patriarch of Constantinople. Migne's edition presents them as separate writings, but some authors have thought that Germanos wrote two texts and then, to fit the scheme of "trilogies", the first was divided. Since there is a great difference between the first (with passages of theological speculation and doxological ones) and the

\footnotetext{
${ }^{1}$ Universidad Nacional de Córdoba. E-mail: elisa.ferrer@unc.edu.ar Fecha de recepción: 21/10/2021; fecha de aceptación: 20/12/2021. DOI: https://doi.org/10.46553/sty.30.30.2021.p241-254
} 
narrative style of the third, it seems appropriate to examine the relationship between the purpose for which Germanos wrote these homilies and the structure he gave them. This work aims to establish that in the first two homilies, which are more elevated in style, the author delves into doctrinal points that illuminate the narrative of the last one: they are not two blocks unified only for the occasion, but it can be recognised the author's intention of providing in the first two the key of how to understand the facts that he relates in the third.

Keywords: Byzantium - narration - theology - homiletics.

Después del Concilio de Calcedonia, celebrado en el 451, y tras la controversia entre Nestorio y Cirilo sobre la conveniencia del nombre de "Madre de Dios" aplicado a la Virgen, la veneración de María como Theotokos se consolidó en el ámbito artístico, en el arquitectónico y sobre todo en el litúrgico. El interés de los predicadores se focalizó en María no sólo como aquella que dio a luz a Dios, sino como objeto de veneración por derecho propio; y en el marco de dicha veneración creció el interés en particular por el final de su vida, rodeado de circunstancias maravillosas.

Hacia los siglos VII-VIII, la fiesta de la Dormición de la Virgen, que celebraba tanto el misterio de su muerte como el de su resurrección, ya se encontraba absolutamente consolidada. Entre los escritos que en esa época existen sobre la historia y la celebración litúrgica de la Dormición de María, se cuentan tres homilías escritas por Germán, Patriarca de Constantinopla. Cabe destacar que si bien la edición de Migne las presenta como tres escritos diferentes, muchos autores consideran que originalmente el autor escribió sólo dos textos, y que más tarde, para adecuarse al esquema de "trilogías" escritas para las vigilias que precedían la celebración de las fiestas, ${ }^{2}$ la primera fue dividida en dos partes, constituidas en textos independientes.

\footnotetext{
${ }^{2}$ Es el caso por ejemplo de las Homilías escritas en ocasión de la misma fiesta de la Dormición por Andrés de Creta o Juan Damasceno.
}

Stylos. 2021; 30 (30); pp. 241-254; ISSN: 0327-8859; E-ISSN: 2683-7900 
Unidas por un mismo tema y escritas en ocasión de una misma celebración, se advierte sin embargo una gran diferencia entre la manera en la que están escritas las dos primeras y el estilo de la tercera: mientras las primeras presentan una combinación de pasajes de especulación teológica con otros sustancialmente doxológicos, la última es de carácter netamente narrativo. Si bien las tres podrían clasificarse en el tipo de "Homilías festivas", las dos primeras se imbrican fuertemente con el tipo teológico, mientras que la tercera muestra más bien características del tipo exegético-dramático.

Las tres reciben el nombre de 'homilía' [ó $\mu \lambda \lambda i ́ \alpha]$, y refieren entonces, como señala Cunningham, ${ }^{4}$ a discursos que generalmente un sacerdote pronunció en un contexto litúrgico en una iglesia. Pero como bien señala la misma autora, la homilética bizantina incluye una variedad de formas literarias y sirve para variados propósitos. Parece oportuno profundizar entonces en la relación que existe entre el objetivo con el que Germán escribió cada una de estas homilías y la estructura que dio a cada una de ellas, para buscar luego aquello que las unifica.

Este trabajo pretende establecer que en las dos primeras homilías escritas en un estilo más elevado y con abundantes recursos retóricos-, el autor profundiza en algunos puntos teológicos y doctrinales esenciales que iluminan la narración de los hechos que realiza en la última, de un estilo más sobrio y más sencillo. No se trata por tanto de dos bloques unificados sólo por la ocasión para la que fueron escritos, sino que se reconoce en el autor la intención de proporcionar en las dos primeras la clave de cómo entender los acontecimientos que relata en la tercera.

\section{INTRODUCCIÓN}

Germán -Obispo de Constantinopla del siglo VII-, escribió tres homilías sobre la Dormición de María, y es en ellas en las que nos proponemos profundizar en la presente comunicación. Dichas homilías aparecen en la edición

\footnotetext{
${ }^{3}$ Según la clasificación de CunNingham (2008: 875-876).

${ }^{4}$ Cunningham (2008: 872).
}

Stylos. 2021; 30 (30); pp. 241-254; ISSN: 0327-8859; E-ISSN: 2683-7900 
de Migne $^{5}$ con los números VI, VII y VIII. El hecho de que hayan sido efectivamente tres homilías ha sido luego muy discutido, y los autores coinciden en general en que en realidad habrían sido originalmente sólo dos, separadas luego en tres, a los fines de poder ser pronunciadas en los tres días de vigilia que precedían a la festividad de la Dormición. ${ }^{6}$

$\mathrm{Al}$ abordar la lectura de las homilías, lo primero que llama la atención es que en tanto las dos primeras están escritas en segunda persona, dirigidas directamente a María, la última lo está en tercera persona, y recién al final, en la breve doxología, aparece la segunda persona, cuando el autor se dirige a María y le suplica su intercesión.

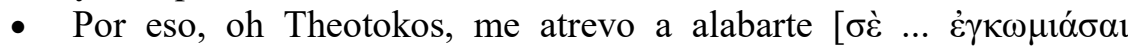
$\tau 0 \lambda \mu \tilde{\omega}-340 \mathrm{~B}]$

- Por tanto, tu ayuda es poderosa para salvación, oh Theotokos

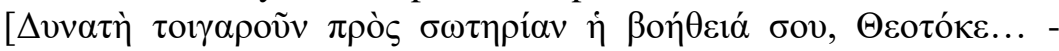
349A]

- Y la narración acerca de la dormición corporal de la dadora de vida

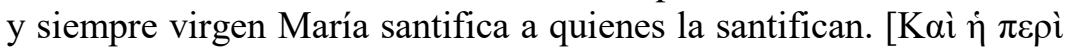

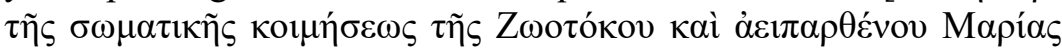

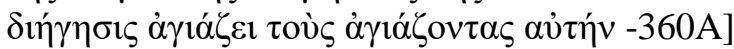

Por otro lado, y antes de comenzar a profundizar en el contenido de cada una de las homilías, resulta significativo señalar que mientras las dos primeras constituyen reflexiones de tipo doxológico y teológico, en las que las menciones a la dormición parecen por momentos un pretexto para profundizar en cuestiones de carácter más bien doctrinal, la tercera es netamente narrativa: en ella encontramos propiamente el relato de los hechos de la muerte y la asunción de María, imbricados -claramente-, con los mismos temas en los que se adentran las dos homilías anteriores.

\footnotetext{
5 Migne, J.P. (1857-1866).

${ }^{6}$ En cualquier caso, y respetando los manuscritos tal cual los hemos recibido, en este trabajo nos referiremos a dichos textos como Homilías I, II y III -aludiendo a los sermones escritos por el Obispo de Constantinopla en ocasión de la fiesta de la Dormición (sin perder de vista que seguramente la I y la II constituyeron una sola unidad en su comienzo).
}

Stylos. 2021; 30 (30); pp. 241-254; ISSN: 0327-8859; E-ISSN: 2683-7900 
Si atendemos a la estructura de las homilías, pareciera por la cantidad de apartados en las que cada una podría dividirse, que la de las dos primeras es más simple que la de la última. Pero todo lo contrario. Cada una de las partes de las primeras es sumamente densa en contenido, mientras que los 'títulos' que caracterizan cada parte de la última refieren a una sucesión de acontecimientos encadenados de manera simple y ordenada.

En la Homilía I, antes de plantearse el autor su 'doble objetivo' de alabar a la Virgen o de centrarse en la Dormición, se multiplican los términos vinculados a la alabanza y a la grandeza de María, todos ellos en un

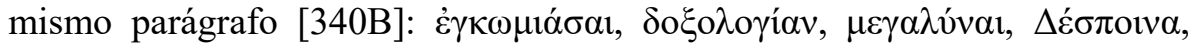

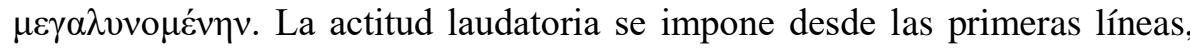
más allá del decurso que luego vaya a seguir el texto, y se sostiene a lo largo del mismo. En la Homilía III, recién al final aparece explícitamente términos vinculados a la alabanza, luego de haber realizado la narración, y caracterizando en este caso su escrito como ú $\mu v o \zeta$.

En las distintas homilías ${ }^{7}$ también aparece explicitado al comienzo el objetivo con el que su autor las escribe. Imbricado en medio de las alabanzas con las que se inicia el primer sermón, Germán se pregunta cuál desarrollar primero de los dos temas que se propone:

- la alabanza de la Virgen: "cantaré las alabanzas de tu compañerismo

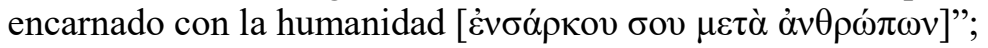

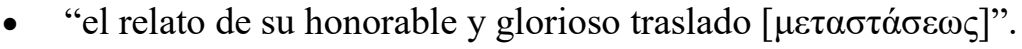

En la Homilía III, en cambio, el objetivo planteado es el de producir alegría: "Pero, de hecho, en unas pocas palabras recordemos su traslado [ $\mu \varepsilon \tau \alpha \sigma \tau \alpha ́ \sigma \varepsilon \omega \varsigma]$ siempre memorable. Pues verdaderamente escuchar la exége-

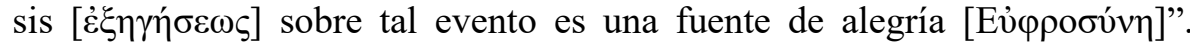
Mientras se puede apreciar que el desarrollo del tercer texto apunta a la concreción de dicho objetivo, en el caso de la primera sólo se cumple el primero de los dos que se propone, ya que nunca se verifica la narración de los hechos vinculados con el momento de la Dormición.

\footnotetext{
${ }^{7}$ La I y la III en realidad, lo que confirma que las dos primeras habrían formado una unidad.
}

Stylos. 2021; 30 (30); pp. 241-254; ISSN: 0327-8859; E-ISSN: 2683-7900 


\section{EL CONTENIDO DE LAS HOMILÍAS}

Los temas en los que Germán profundiza con más detenimiento son la Encarnación y el rol de María como Mediadora o Intercesora de los hombres: en la Homilía I se advierte un mayor énfasis en la Encarnación, mientras que en la Homilía II el foco está puesto más bien en la Intercesión. ${ }^{8}$

\section{LA ENCARNACIÓN}

El Obispo de Constantinopla desempeñó un papel central en la discusión sobre el Monotelismo, que supone aceptar la naturaleza humana de Cristo junto a la divina. Y naturalmente el rol de María, como quien pudo hacer realidad la humanidad de Cristo, se vuelve fundamental. En ese marco seguramente resulta significativo que el autor subraye tanto en sus sermones sobre la Virgen el tema de la Encarnación. En la Homilía I -casi al comienzo-,

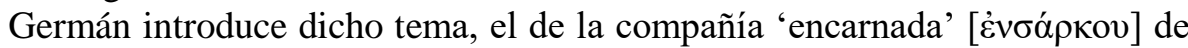
María con la humanidad [340C]. A partir de ese momento la cuestión prácticamente atraviesa las dos primeras homilías, tratándose a veces de textos reflexivos y otras de simples alusiones. Casi inmediatamente aparece un pasaje en el que el autor realiza propiamente una reflexión teológica sobre la Encarnación [340D-344B]. El pasaje -que se desprende de una mención a la Dormición de María [cuando fuiste trasladada $-\mu \varepsilon \tau \alpha \tau \varepsilon \theta \varepsilon i ̃ \sigma \alpha$ ], es extenso y tras relacionar los roles de María en la tierra y en el cielo con la Encarnación, profundiza en el tema teológico de la pericoresis del Padre y el Hijo, vinculando claramente su discurso con el credo niceno-constantinopolitano.

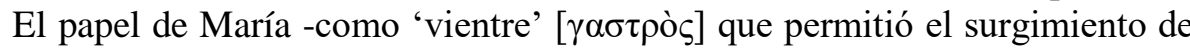
Cristo como hombre, se vuelve fundamental. Y así se multiplican, en las dos primeras homilías, términos que explícitamente refieren a la Encarnación. ${ }^{9}$

\footnotetext{
8 Junto a esos dos temas fundamentales, se verifican recurrentes menciones a la incorruptibilidad del cuerpo de María y a su virginidad. E imbricadas en el desarrollo de esos grandes temas, encontramos las menciones a la Dormición. Todo ello en un contexto marcado fuertemente por la alabanza y la glorificación de la Virgen.

${ }^{9}$ Algunos de ellos se concentran en este mismo pasaje, otros aparecen a lo largo del sermón:

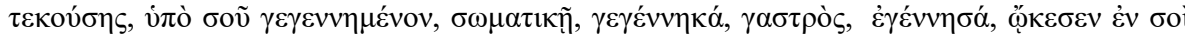

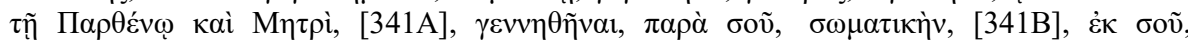


A partir de su condición de Madre de Dios, Germán explica la Dormición de la Virgen, así como el hecho de que su cuerpo no sufriera la corrupción:

Porque no era posible para ti, siendo un recipiente que contiene a Dios [ $\theta \varepsilon \sigma \chi \omega ́ \rho \eta \tau o v]$, ser destruida por la disolución [ảv $\alpha \lambda \hat{\sigma} \sigma \varepsilon \omega \varsigma]$ de la tierra corruptora de cadáveres. Porque ya que el que se vació en ti

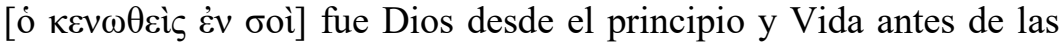

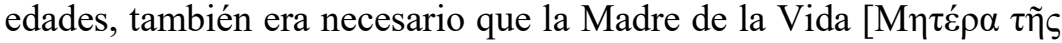
Z $\omega \tilde{\eta} \varsigma]$ se convirtiera en compañera con la Vida, y experimentara la

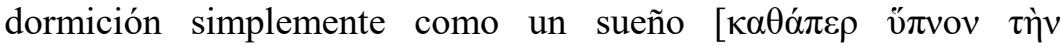

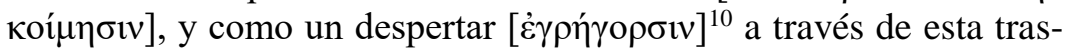

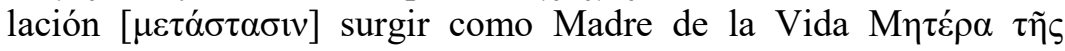
$\mathrm{Z} \omega \tilde{\eta} \varsigma]$.

En la comparación que Germán realiza de Eva y María [349A-B] ${ }^{11}$ destaca su rol en la Encarnación, la cual aparece nuevamente vinculada con su Dormición; en tanto ella es la madre de Cristo puede pasar a la Vida:

Porque eres la madre de la vida verdadera [ $\dot{\alpha} \lambda \eta \theta v v \tilde{\eta} \varsigma \zeta \omega \tilde{\eta} \varsigma \dot{\eta} \mu \eta \dot{\tau} \tau \rho]$.

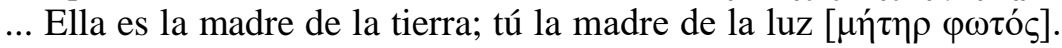

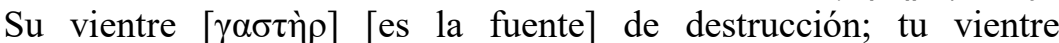

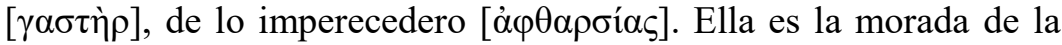

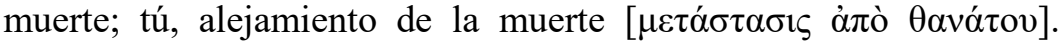
[349A]

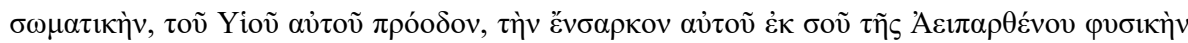

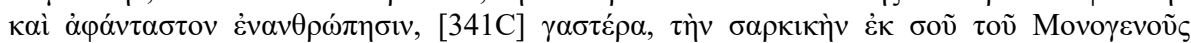

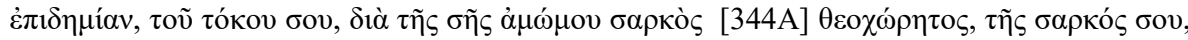

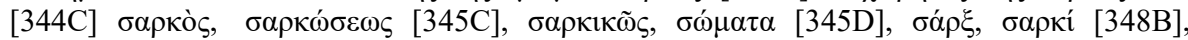

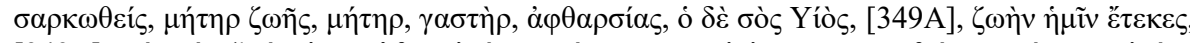

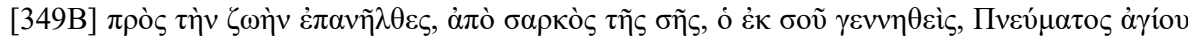

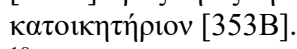

${ }^{10}$ Exactamente los mismos términos aparecen en la Homilía III, en el relato del momento de

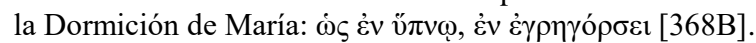

${ }^{11}$ En la Homilía III aparece también una breve mención contrastando a María con Eva: "Ven con regocijo. Abre tú el paraíso que Eva cerró", le dice Cristo a su Madre.

Stylos. 2021; 30 (30); pp. 241-254; ISSN: 0327-8859; E-ISSN: 2683-7900 
En la conclusión de la Homilía II nuevamente aparece vinculada la Dormición de María y la incorruptibilidad de su cuerpo, con su rol de Theotokos, fuertemente subrayado: ${ }^{12}$

...Y por el bien de esto, era verdaderamente apropiado que tu cuerpo receptor de Dios [ $\theta \varepsilon \eta \delta \delta$ ́ov] no estuvieras encerrado por una corrup-

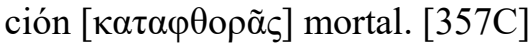

\section{EL ROL DE MEDIADORA E INTERCESORA}

Germán plantea en todo momento que la posición de María como madre constituye la razón de su poder como intercesora: el rol de mediadora está íntimamente ligado a la Encarnación.

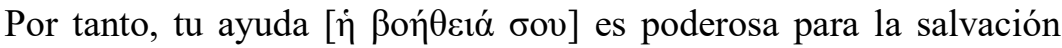

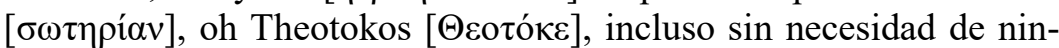
gún otro abogado [ $\pi \alpha \rho \alpha \theta \dot{\varepsilon} \tau o v]$ ante Dios. Porque eres la madre de la

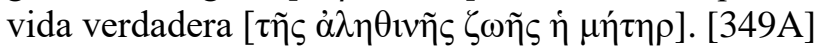

¿cómo es aceptable que dejes a los hombres huérfanos [ó $\rho \propto \alpha v o v ̀ s]$

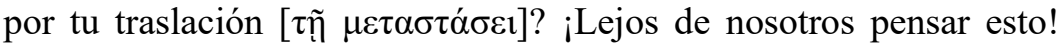
Porque ... habiendo sido trasladada $[\mu \varepsilon \tau \alpha \tau \varepsilon \theta \varepsilon \tilde{\sigma} \sigma \alpha]$ no has alejado de la humanidad tu consejo espiritual. [344C] $]^{13}$

Es por eso que desde el comienzo de la Homilía I -en la que aparece mucho más acentuado el tema de la Encarnación, el papel de María como protectora de los hombres va también introduciéndose:

\footnotetext{
${ }^{12}$ El término se repite tres veces.

${ }^{13}$ Una idea semejante se advierte en 357B, en la que se subraya que María no dejá huérfana a la humanidad y la y sigue acompañando después de su Dormición: "por lo que también creemos que te veremos yendo con nosotros como líder incluso después de tu partida del

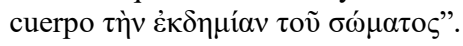

Stylos. 2021; 30 (30); pp. 241-254; ISSN: 0327-8859; E-ISSN: 2683-7900 


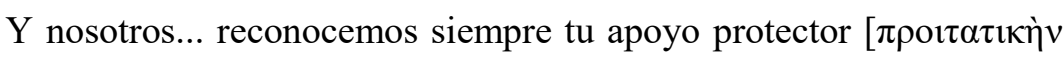

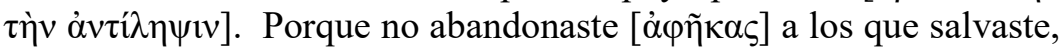

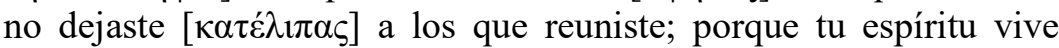

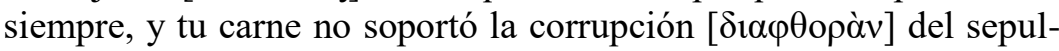
cro. $[345 \mathrm{~A}]$

Y en la breve conclusión de la Homilía I [348C] vuelve a aparecer la misma idea, vinculada en este caso directamente con la Dormición: Cristo llevó

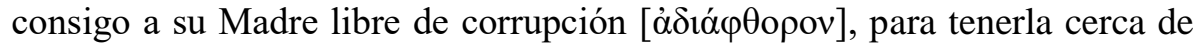

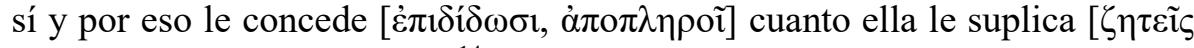

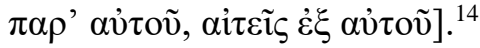

En la Homilía II la cuestión del rol de la Virgen como mediadora tiene una presencia más recurrente y profunda. La misma prácticamente comienza con la cita arriba mencionada en la que se la califica como 'abogada', y luego la idea se reitera, fuertemente ligada a la Dormición: "pasaste a la vida

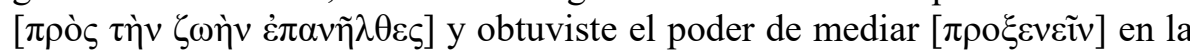

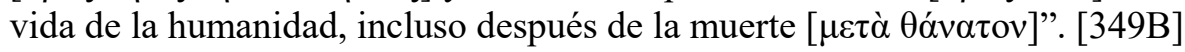

Ese poder de mediación, ese rol de ayudar a los hombres, es ilustrado en lo que Roth llama una 'letanía', subrayada por la reiteración de la expre-

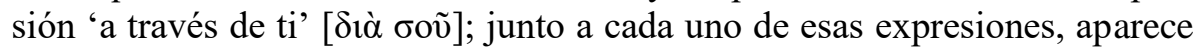
un epíteto diferente atribuido a María:

...porque tu defensa $[\pi \rho 0 \sigma \tau \alpha \sigma i ́ \alpha$ es vivir, y tu intercesión $[\pi \rho \varepsilon \sigma \beta \varepsilon i ́ \alpha$ es vida, y tu protección [ $\sigma \kappa \varepsilon \dot{\pi}\rceil \eta$ es incesante... Nadie está lleno con

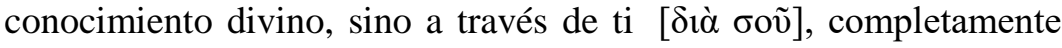

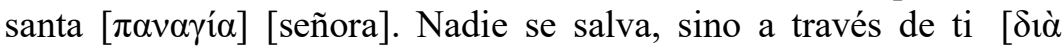

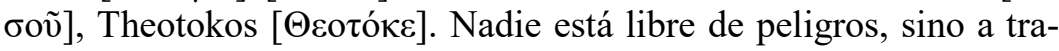

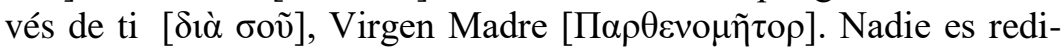

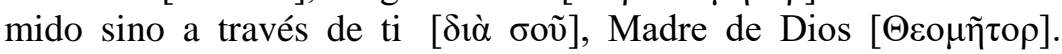
[349B]

\footnotetext{
14 Notemos cómo se reitera la idea de la incorruptibilidad del cuerpo de María, tema vinculado estrechamente en estas homilías a la Dormición, la Encarnación y la Mediación pero en el que no nos resulta posible profundizar en esta oportunidad.
}

Stylos. 2021; 30 (30); pp. 241-254; ISSN: 0327-8859; E-ISSN: 2683-7900 
Se suceden a continuación una suerte de anáforas, que con distintos

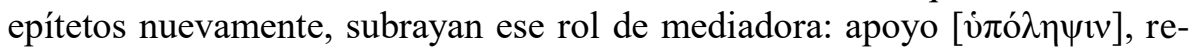
fugio $[\pi \rho 0 \sigma \varphi v ́ \gamma 10 v]$, ayuda $[\beta o \eta ́ \theta \varepsilon 1 \alpha v]{ }^{15}[352 \mathrm{~B}]$. Y sigue luego una extensa serie de otros veintitrés 'epítetos' [352C-353A] que identifican a la Virgen

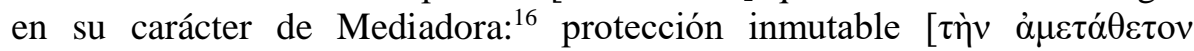

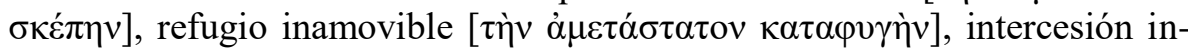

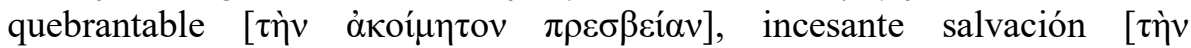

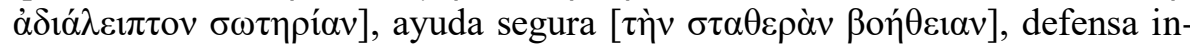

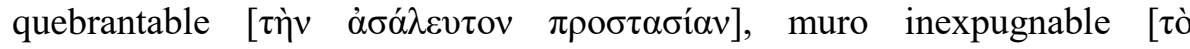

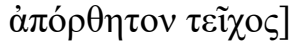

Tras un nuevo pasaje laudatorio, el autor nos remite a la Dormición [356A]; quien es capaz de reconocerla, sabe que María es su compañera y protectora:

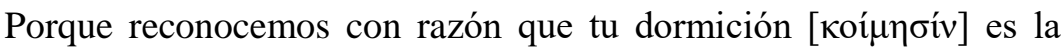
vida, y nosotros confíamos en tenerte como compañera [бúvoıkóv]. Y cuando la tribulación $[\theta \lambda i ́$ is $]$... estás cerca, buscándote estamos rescatados $[\lambda v \tau \rho o v ́ \mu \varepsilon \theta \alpha] . .$. Y cuando entre todos estamos turbados $[\mu \varepsilon \rho \mu \nu \omega \dot{\mu} \mu \varepsilon \theta \alpha]$, confiamos en que estás con nosotros [ $\left[\mu \varepsilon \theta^{\prime} \dot{\eta} \mu \tilde{\omega} v\right]$.

Los pasajes que en esta segunda homilía se refieren a la presencia de María junto a la humanidad después de su partida, a su protección, a su función de trasladar a Dios lo que los hombres necesitan, podrían multiplicarse. Resulta indudable entonces destacar que Germán quiere comunicar a sus oyentes la certeza de que no están solos, y de que en la Virgen siempre encontrarán una compañera que no los ha dejado huérfanos tras su Dormición. Esa certeza es capaz de transmitir esperanza al hombre frente a la muerte: Dios jamás igno-

\footnotetext{
${ }^{15}$ Intercalados con estos pasajes que se refieren al rol de María como intercesora, aparecen otros caracterizados por la alabanza y la glorificación de la Virgen. Constituyen el componente doxológico propio de la celebración para la que fueron escritas, que no se advierte en la tercera homilía. La alabanza surge de una actitud agradecida frente a la protección -de modo que se ligan nuevamente gloria y mediación. En sólo siete líneas leemos:

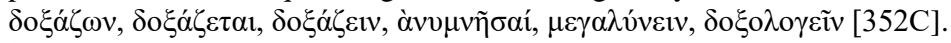

${ }^{16}$ Incluimos sólo los más significativos.
}

Stylos. 2021; 30 (30); pp. 241-254; ISSN: 0327-8859; E-ISSN: 2683-7900 


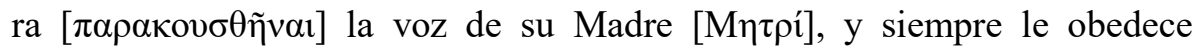
[ $\pi \varepsilon 1 \theta \alpha \rho \chi \varepsilon \tilde{i}]$ [352A]. Hemos intentado mostrar cómo en las dos primeras homilías Germán profundiza en dos cuestiones teológicas importantes en aquel momento: la Encarnación y el rol de María como intercesora $;{ }^{17}$ y vinculada con cada uno de esos temas, su Dormición.

En la tercera homilía -según mencionamos- no aparecen pasajes de tipo argumentativo sobre ninguna de aquellas cuestiones, pero sí permanentes alusiones o términos vinculados a ellas. La primera vinculación indudable se da ya en el planteo de los objetivos. Si bien son diferentes, según ya señalamos, se encuentran unificados por un mismo tema -la Dormición-, y el término utilizado para referirse a ella es exactamente el mismo: $\mu \varepsilon \tau \alpha \sigma \tau \alpha ́ \sigma \varepsilon \omega \varsigma$ [340C y 360B]. La cuestión de la Trinidad -larga y profundamente explicada en la primera Homilía-, se refleja en apenas una mención en la Homilía III: "Verá la gloria de mi Padre tu alma inspirada en Dios. Verá la gloria de su Hijo unigénito tu cuerpo sin mancha. Verá la gloria del Espíritu Santo tu espíritu puro" [361B].

El tema de la Encarnación aparece en el último sermón bien al comienzo, cuando Germán introduce brevemente el tema ("porque por la resu-

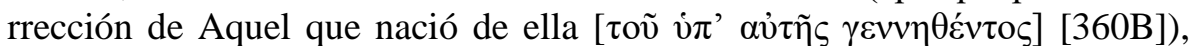
luego fundamentalmente en las palabras que Cristo dirige a su Madre, intentando llevarle tranquilidad frente a la muerte que se le avecina, y finalmente ${ }^{18}$ en las palabras de Pablo a la Virgen, así como en la actitud de los apóstoles ante su cuerpo María. En la mayoría de los casos aparece vinculado con la Dormición:

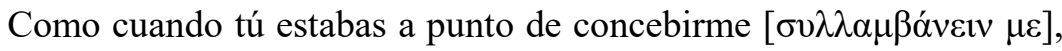
recibiste un anuncio de gozo, alégrate también ahora cuando eres in-

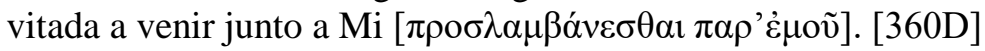

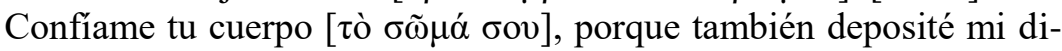

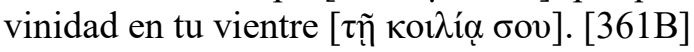

\footnotetext{
${ }^{17}$ Por la naturaleza de esta comunicación no nos resulta posible hacerlo en esta oportunidad, pero junto a esos temas, son también fuertemente subrayados la incorruptibilidad del cuerpo de María y su virginidad.

${ }^{18}$ Las últimas frases que citamos.
}

Stylos. 2021; 30 (30); pp. 241-254; ISSN: 0327-8859; E-ISSN: 2683-7900 


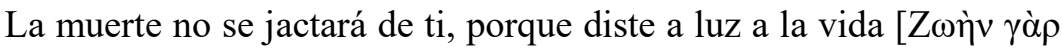

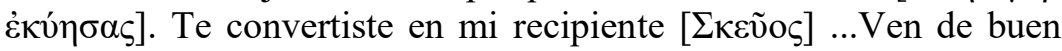

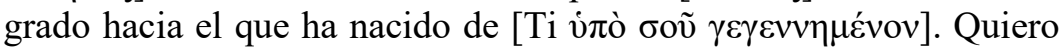
regocijarte como debería un hijo, pagarte el alquiler del útero ma-

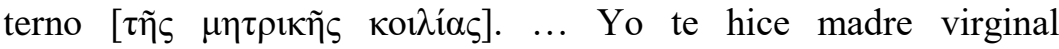

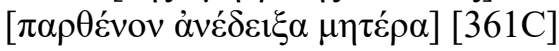

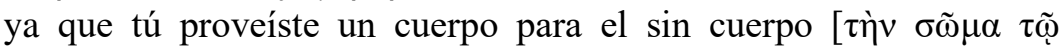
$\dot{\alpha} \sigma \omega \mu \alpha ́ \tau \omega]$ en el que se cubrió [368A]

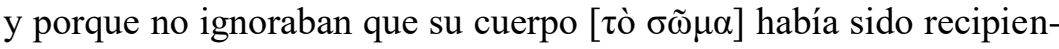

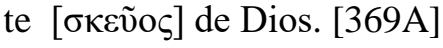

El rol de María como protectora, intercesora y mediadora -sin que exista tampoco una reflexión argumentativa sobre la cuestión-, prácticamente atraviesa la Homilía III. Al igual que en la Homilía II, encontramos una larga enumeración de epítetos atribuidos por Cristo a su Madre que la describen

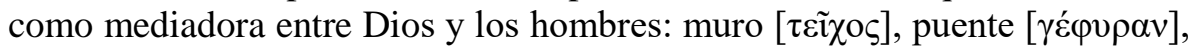
arca $[\kappa \iota \beta \omega \tau o ̀ v]$, bastón $[\beta \alpha \kappa \tau \eta \rho i ́ \alpha v]$, intercesión $[\pi \rho \varepsilon \sigma \beta \varepsilon i ́ \alpha v]$, escalera

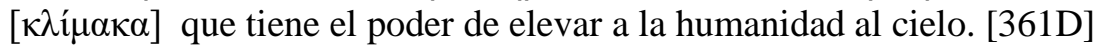

También las palabras de los apóstoles y de Pablo a María, al conocer su inminente partida, subrayan la confianza en su papel como intercesora tras su Dormición: confían en que tras su Dormición será su intercesora [ $\mu \varepsilon \sigma i \tau i ́ v-365 \mathrm{C}]$ y se proponen predicar que habiendo sido trasladada

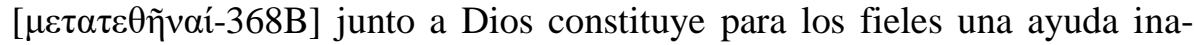

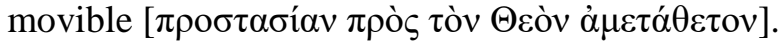

Estas palabras puestas en boca de los discípulos condensan de manera sencilla-a nuestro parecer-, lo fundamental de lo que Germán quiere transmitir a sus fieles en esta Homilía:

- la doctrina de la Dormición de María (para celebrar la cual justamente fue redactado el sermón);

- la posibilidad de salvación que a través de ella existe para la humanidad;

- la certeza de que su presencia junto a Dios garantiza a los hombres su ayuda y posibilidad de intercesión.

La misma idea se ve reforzada en la inquietud manifestada por quienes rodeaban a María al saber de su partida, quienes le rogaban que no los dejara

Stylos. 2021; 30 (30); pp. 241-254; ISSN: 0327-8859; E-ISSN: 2683-7900 
huérfanos [ỏ $\varphi \propto \alpha v ı \theta \tilde{\eta} v \alpha 1$ ] [365A], y en la garantía transmitida por Cristo de

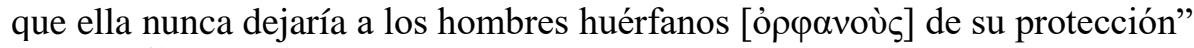
[360D]). ${ }^{19}$

Según hemos podido advertir en el recorrido realizado por los textos, el hecho de que las dos primeras homilías sean tan diferentes en su forma a la tercera no resulta en absoluto contradictorio: los mismos temas que son expresamente profundizados en aquellas, iluminan los acontecimientos relatados en la última, en la que tienen también una presencia permanente: en menciones o alusiones que distribuidas a lo largo de la narración ofrecen -de manera sencilla y fácilmente aprehensible-, un enmarque doctrinario al relato de la Dormición. El discurso directo que según mencionamos al principio caracteriza la tercera homilía, así como el intercambio entre los personajes, que se presentan directamente ante el auditorio, favorece que los fieles puedan involucrarse en el entramado doctrinal y teológico que se les transmite de una manera vívida y sencilla.

Para Germán María es, ante todo, el instrumento humano que permite la Encarnación. De su realidad de Madre deriva su rol fundamental como intercesora y protectora de los hombres: tras su Dormición que le ha permitido alcanzar la Vida junto a su Hijo, puede seguir acompañando a quienes todavía están en la tierra e interceder por sus peticiones ante Dios. Esta cuestión sobre la que el autor se detiene en pasajes de carácter reflexivo y argumentativo en las primeras homilías, es la misma que atraviesa la última, transmitida de una manera que seguramente sirvió para comunicar de modo simple la esperanza que pueden albergar al saber que tienen quien interceda por ellos y que además existe la esperanza de la vida junto a Dios tras la muerte.

\section{REFERENCIAS BIBLIOGRÁFICAS}

CUnNinghaM, M. "Homilies", 872-882. En: Jeffreys, E.; Haldon, J.; Cormack, R. (eds.) The Oxford Handbook of Byzantine Studies. Oxford:

\footnotetext{
${ }^{19}$ Se retoma aquí el mismo término que leímos más arriba [344C]: ¿cómo es aceptable que

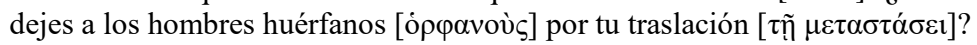

Stylos. 2021; 30 (30); pp. 241-254; ISSN: 0327-8859; E-ISSN: 2683-7900 
Oxford University Press, 2008.

Chevalier, C., "Les trilogies homilétiques dans l'élaboration des fêtes Mariales, 650-850", Gregorianum 193718 : 361-378.

Daley, B. J., On the Dormition of Mary: Early Patristic Homilies. Crestwood: St. Vladimir's Seminary Press, 1998.

DALEY, B. J., "“At the Hour of Our Death': Mary's Dormition and Christian Dying in Late Patristic and Early Byzantine Literature", DOP 2001: 71-89.

JugIE, M., "Homèlies mariales byzantines" (II), Patrologia Orientalis 1926 XIX : 375-405.

Migne, J.P., Patrologiae cursus completus. Series graeca. Paris: Garnier, 1857-1866.

PONS PONS, G. (trad.), Germán de Constantinopla. Homilías mariológicas. Madrid: Ciudad Nueva, 1990.

Roth, G. E., Paradox Beyond Nature: the Marian Homilies of Germanos I, Patriarch of Constantinople (715-730). Dayton: University of Dayton, 2001. 